\title{
Article
}

\section{Transcriptional Controls for Early Bolting and Flowering in Angelica sinensis}

\author{
Mengfei $\mathrm{Li}^{1,2, * \mathbb{D}}$, Jie Li ${ }^{1}$, Jianhe Wei ${ }^{2, *}$ and Paul W. Paré ${ }^{3} \mathbb{D}$ \\ 1 State Key Laboratory of Aridland Crop Science, Gansu Agricultural University, Lanzhou 730070, China; \\ lijie9654@163.com \\ 2 Institute of Medicinal Plant Development, Chinese Academy of Medical Sciences \& Peking Union Medical College, \\ Beijing 100193, China \\ 3 Department of Chemistry and Biochemistry, Texas Tech University, Lubbock, TX 79409, USA; \\ paul.pare@ttu.edu \\ * $\quad$ Correspondence: lmf@gsau.edu.cn (M.L.); jhwei@implad.ac.cn (J.W.)
}

Citation: Li, M.; Li, J.; Wei, J.; Paré, P.W. Transcriptional Controls for Early Bolting and Flowering in Angelica sinensis. Plants 2021, 10, 1931. https://doi.org/10.3390/ plants10091931

Academic Editor: Agnes Farkas

Received: 23 August 2021

Accepted: 14 September 2021

Published: 16 September 2021

Publisher's Note: MDPI stays neutral with regard to jurisdictional claims in published maps and institutional affiliations.

Copyright: (C) 2021 by the authors. Licensee MDPI, Basel, Switzerland. This article is an open access article distributed under the terms and conditions of the Creative Commons Attribution (CC BY) license (https:/ / creativecommons.org/licenses/by/ $4.0 /)$.
Abstract: The root of the perennial herb Angelica sinensis is a widely used source for traditional Chinese medicines. While the plant thrives in cool-moist regions of western China, early bolting and flowering (EBF) for young plants significantly reduces root quality and yield. Approaches to inhibit EBF by changes in physiology during the vernalization process have been investigated; however, the mechanism for activating EBF is still limited. Here, transcript profiles for bolted and unbolted plants (BP and UBP, respectively) were compared by transcriptomic analysis, expression levels of candidate genes were validated by qRT-PCR, and the accumulations of gibberellins $\left(\mathrm{GA}_{1}, \mathrm{GA}_{4}, \mathrm{GA}_{8}, \mathrm{GA}_{9}\right.$ and $\mathrm{GA}_{20}$ ) were also monitored by HPLC-MS/MS. A total of over 72,000 unigenes were detected with ca. 2600 differentially expressed genes (DEGs) observed in the BP compared with UBP. While various signaling pathways participate in flower induction, it is genes associated with floral development and the sucrose pathway that are observed to be coordinated in EBF plants, coherently up- and down-regulating flowering genes that activate and inhibit flowering, respectively. The signature transcripts pattern for the developmental pathways that drive flowering provides insight into the molecular signals that activate plant EBF.

Keywords: Angelica sinensis; early bolting and flowering; transcriptomic analysis; gibberellin metabolism; sucrose metabolism

\section{Introduction}

Angelica sinensis (Oliv.) Diels (Family Umbelliferae) is a perennial herb distributed mainly in cool-moist regions of western China at elevations ranging from 2200 to $3000 \mathrm{~m}$ [1-3]. Roots (Danggui) are prepared as a traditional Chinese tonic reported to nourish the blood and harmonize vital energy [4]. Over 140 root metabolites have been identified, including polysaccharides, organic acids, phthalides, and essential oils [5,6]. These compounds confer pharmacological activities including: anti-inflammatory, antioxidant, anticancer, and cardio-cerebrovascular effects [7-9].

Due to an increasing demand for traditional Chinese medicines, $A$. sinensis is farmed to meet commercial demand [3]. For industrialized planting, seeds are sown in early summer, plants are collected in Fall and overwinter indoors; the following spring, seedlings are planted for vegetative growth and are either harvested in Fall of the second year to obtain non-lignified roots or kept in the field till mid-summer of the third year for seed collection (Figure S1) [10]. Early bolting and flowering (EBF) occurs in the second year in up to $40 \%$ of the plants, substantially reducing root yield and quality due to lignifications of roots and degradations of bioactive compounds [1,11,12]. For the EBF to occur, the plant must experience vernalization and long-day (LD) conditions; thus, avoiding vernalization or LD 
conditions can reduce EBF [13-15]. In addition, the EBF is also affected by varieties [3], seedling age and weight [16], latitude and longitude [17], and soil conditions [18,19].

The transition from vegetative growth to flowering involves multiple signaling pathways that are transcriptionally regulated including: photoperiodic, autonomous/vernalization, sucrose, and gibberellin (GA) pathways [20]. All pathways converge by increasing the expression of the two meristem identity genes: SUPPRESSOR OF OVEREXPRESSION OF CONSTANS1 (SOC1) that is also known as AGAMOUSLIKE 20 (AGL20) and LEAFY (LFY). SOC1 and $L F Y$, in turn, regulate the floral homeotic genes to produce the floral organs $[20,21]$. The photoperiodic pathway is initiated by phytochromes and cryptochromes. The interaction of photoreceptors with a circadian clock activates the expression of the gene CONSTANS $(\mathrm{CO})$ that encodes a zinc-finger transcription factor that promotes flowering. In the dual autonomous/vernalization pathway, flowering occurs either in response to internal signals, the production of a fixed number of leaves, or to low temperatures that reduces the expression of the flowering repressor gene FLOWERING LOCUS C (FLC). The sucrose pathway reflects the metabolic state of the plant and sucrose stimulates flowering by increasing $L F Y$ expression. Lastly, the GA pathway can participate in early flowering and for flowering under noninductive short days.

Besides the previously mentioned developmental pathways that promote flowering, Arabidopsis mutants that exhibit early flowering have revealed the involvement of genes that repress flowering. For example, EMBRYONIC FLOWER1 (EMF1) and EMF2 act as strong flowering repressors [22]; CURLY LEAF (CLF) by preventing the expression of the floral meristem identity gene AGAMOUS (AG) during vegetative growth [23]; EARLY BOLTING IN SHORTDAYS (EBS) participates in the regulation of flowering time by specifically repressing the expression of FLOWERING LOCUS T (FT) [24]; Cyclic dof factor 2 (CDF2) delays flowering by repressing $C O$ transcription [25]; and MicroProtein $1 A(M I P 1 A)$ and MIP1B repress flowering by forming heterodimeric complexes [26].

Currently, little research focuses on physiological and molecular changes during vernalization of $A$. sinensis seedling, and researches related to growing stage are limited. Specifically, Lu et al. [27] reported that the levels of soluble sugars and protein decreased during the growing stage. Yu et al. [28] found that 5094 genes were differentially expressed in the apical meristem of plants presenting vegetative growth compared to flower buds of early flowering plants, and 13 DEGs were involved in photoperiodic, vernalization, sucrose, and GA pathway. Our previous studies found that 558 genes co-expressed during the four photoperiodic stages of plant growth and 38 DEGs were involved in photoperiodic, hormone signaling, carbohydrate metabolism, and floral development [29].

To date, although the levels of amino acids, $\mathrm{GA}_{3}$, zeatin riboside and polyamines, and the activities of peroxidase and polyphenoloxidase in bolting plants (BP) compared to unbolted plants (UBP) have been investigated [27], early bolting-dependent changes that impact genes expression and GAs metabolism have not been investigated and identified. In this study, the BP and UBP were measured by transcriptomic analysis and 40 DEGs associated with EBF were mapped on pathways involved in flowering control. Gene expression levels were validated with qRT-PCR, and down-stream GA metabolites were profiled by HPLC-MS/MS.

\section{Materials and Methods}

\subsection{Plant Material}

Mature seeds of 3-year-old A. sinensis (Mingui No. 1) were permitted to collect from the county-owned garden located in Minxian county (2520 m a.s.1.; $34^{\circ} 28^{\prime} 33^{\prime \prime} \mathrm{N}, 104^{\circ} 05^{\prime} 51^{\prime \prime}$ E) of Gansu province, P. R. China in July 2017. The species was identified by professor Ling Jin (Gansu University of Chinese Medicine, Lanzhou, Gansu, China). A voucher specimen (No. 20200182) was deposited in the herbarium of College of Life Science and Technology, Gansu Agricultural University, Lanzhou, Gansu, China. Seeds were pre-treated in water $\left(30^{\circ} \mathrm{C}\right)$ for $24 \mathrm{~h}$ and sown at a soil depth of $0.5 \mathrm{~cm}$ located in Minxian county $(2730 \mathrm{~m}$ a.s.l.; $34^{\circ} 28^{\prime} 8^{\prime \prime} \mathrm{N}, 104^{\circ} 36^{\prime} 22^{\prime \prime} \mathrm{E}$ ) in June 2018. Seedlings were dug up in October 2018, aired in 
the shade for approximately 15 days and then stored in a natural-rain-proof environment for the winter.

On April 3, 2019, the stored seedlings (root tip diameter 4.5-5.0 mm) were transplanted into pots (diameter $17 \mathrm{~cm}$, depth $20 \mathrm{~cm}$; one seedling per pot) with nutrition matrix and seedlings were greenhouse grown with controlling matrix volumetric moisture content of $60-70 \%$, light condition of $10-12 \mathrm{~h}$ per day and air temperature $15-22{ }^{\circ} \mathrm{C}$. No additional fertilizer was applied after the transplant. With plant growth and development, some plants began to initiate flower bud differentiation and then $\mathrm{BF}$, other plants kept on vegetative growth with NBP. On 3 July 2019, samples including the second-tip leaves and lateral roots $(1: 1, \mathrm{~g} / \mathrm{g}$ fresh weight) from BP and UBP (Figure S2) were collected $(n=20$ plants with homogeneous growth potential) and then flash frozen in liquid nitrogen for transcriptomic analysis and GA metabolite analysis.

\subsection{Total RNA Isolation and Illumina Sequencing}

Total RNA samples were isolated according to our previous literature [29]. RNA sequencing was conducted using an Illumina HiSeq ${ }^{\mathrm{TM}} 4000$ platform by Gene De novo Biotechnology Co., Ltd. (Guangzhou, China).

\subsection{Sequence Filtration, Assembly and Unigene Expression Analysis}

Sequence filtration, assembly, and unigene expression analysis were conducted according to our previous literature [29]. Briefly, raw reads were filtered by removing reads containing adapters, unknown nucleotides and low-quality bases. De novo assembly of clean reads used a Trinity software [30]. The expression level of each transcript was normalized to reads per $\mathrm{kb}$ per million (RPKM) value [31]. In this study, the level of differential expression for each transcript with a criterion of $\mid \log _{2}$ (fold-change) $\mid \geq 1$ and $p$ value $\leq 0.05$ to identify DEGs between BP and UBP.

\subsection{Basic Annotation of DEGs and Gene Cluster Analysis}

Unigenes were annotated against the databases including: NCBI non-redundant protein (NR), Swiss-Prot protein, Kyoto Encyclopedia of Genes and Genomes (KEGG), euKaryotic orthologous groups of proteins (KOG), and gene ontology (GO) by using a BLASTx procedure with an e-value $\leq 10^{-5}$ [32]. Molecular Evolutionary Genetics Analysis (MEGA) 7.0 was used for the gene cluster analysis (Figure S3).

\section{5. $q R T-P C R$ Validation}

The relative expression levels (RELs) were validated according to our previous literature [29]. Briefly, total RNA was extracted using a plant RNA kit. Primer sequences of the 40 DEGs (Table S1) were designed in primer-blast of NCBI. First-strand cDNA was synthesized using a FastKing RT kit. PCR amplification was carried out using a SuperReal PreMix. Actin was used as an internal reference and the REL was calculated using a $2^{-\Delta \Delta C t}$ method [33].

\subsection{GA Quantification and Identification}

Samples were ground into powder in liquid nitrogen, $1.0 \mathrm{~g}$ sample was soaked in acetonitrile $(10 \mathrm{~mL})$ and agitated at $4{ }^{\circ} \mathrm{C}$ for $8 \mathrm{~h}$, then centrifuged at $13,000 \mathrm{r} / \mathrm{min}$ and $4{ }^{\circ} \mathrm{C}$ for $5 \mathrm{~min}$. Following exhaustive extraction $(\times 3)$, the upper portion was pooled and dried with nitrogen gas in the dark. Dried residue was re-dissolved in methanol $(400 \mu \mathrm{L})$ and filtered with $0.22 \mu \mathrm{m}$ durapore membrane. The reference standard of the $5 \mathrm{GAs}\left(\mathrm{GA}_{1}, \mathrm{GA}_{4}\right.$, $\mathrm{GA}_{8}, \mathrm{GA}_{9}$, and $\mathrm{GA}_{20}$ ) was dissolved in methanol to make concentrations $0.1,0.2,0.5,2$, $5,20,50$, and $200 \mathrm{ng} / \mathrm{mL}$. Samples $(2 \mu \mathrm{L})$ were quantified and identified using a HPLC (Agilent1290, USA)-MS/MS (QTRAP 6500, AB SCIEX, USA) by Shanghai Biotree biotech Co., Ltd. (Shanghai, China). Methanol (A) and $\mathrm{H}_{2} \mathrm{O}$ (B) were the gradient elution: 0-1 min $20 \%$ A, 1-9 min A increasing up to $80 \%, 9-10 \mathrm{~min} 90 \% \mathrm{~A}, 10-10.1 \mathrm{~min}$ A decreasing down to $20 \%$, and $10.1-15 \min 20 \% \mathrm{~A}$. Representative chromatograms of reference standard of the 
5 GAs are shown in Figure S4, and representative chromatograms of the BP and UBP are shown in Figure S5. The content of the 5 GAs was calculated based on calibration curves (Table S2).

\subsection{Soluble Sugar Measurement}

Soluble sugar was measured using a sulfuric acid-phenol protocol [34]. A dried powder $(1.0 \mathrm{~g})$ was soaked in $95 \% \mathrm{EtOH}(25 \mathrm{~mL})$ for $72 \mathrm{~h}$ at $22{ }^{\circ} \mathrm{C}$ and then centrifuged $\left(4{ }^{\circ} \mathrm{C}, 8000 \mathrm{r} / \mathrm{min}, 10 \mathrm{~min}\right)$. Extracts $(30 \mu \mathrm{L})$ were added into $9 \%$ phenol reagent $(1 \mathrm{~mL})$, sulfuric acid $(3 \mathrm{~mL})$ was added after oscillation and then reacted at $22{ }^{\circ} \mathrm{C}$ for $30 \mathrm{~min}$. Absorbance was measured at $485 \mathrm{~nm}$, soluble sugar content was evaluated based on $\mathrm{mg}$ of Suc.

\subsection{Statistical Analysis}

All the measurements were performed using three replicates. A t-test for independent samples was performed and SPSS 22.0 was used, with $p<0.05$ as the basis for significant differences.

\section{Results}

\subsection{Global Gene Analysis}

A robust data set was collected (Figure S6) and after data filtering, 60.7 and 52.4 million high-quality reads were obtained for the BP and UBP, respectively; 44.7 and 37.4 million unique reads as well as 7.8 and 6.4 million multiple reads were mapped. From the 72,502 compiled genes and annotated against the databases including NR, SwissProt, KEGG, KOG, and GO (Tables 1 and 2, Figures S7-S11), 2645 DEGs were obtained (Figure S12). Of these 2645 DEGs, 369 genes were unidentified by SwissProt, KOG, GO, and KEGG databases. Of the 2276 identified DEGs, 1584 genes with known function were partitioned into being 738 UR and 846 DR. Based on biological function and physiological characteristics, genes were divided into 11 categories: photosynthesis/energy (79), primary metabolism (285), secondary metabolism (80), hormone biosynthesis (34), bio-signaling (201), cell morphogenesis (197), polynucleotide biosynthesis (87), transcription factor (167), translation (119), transport (233), and stress response (102) (Figure 1). Based on flower driving genes characterized in higher plants [20], 40 DEGs (29 UR and 11 DR) were identified as potential regulatory genes for EBF (Figure 1).
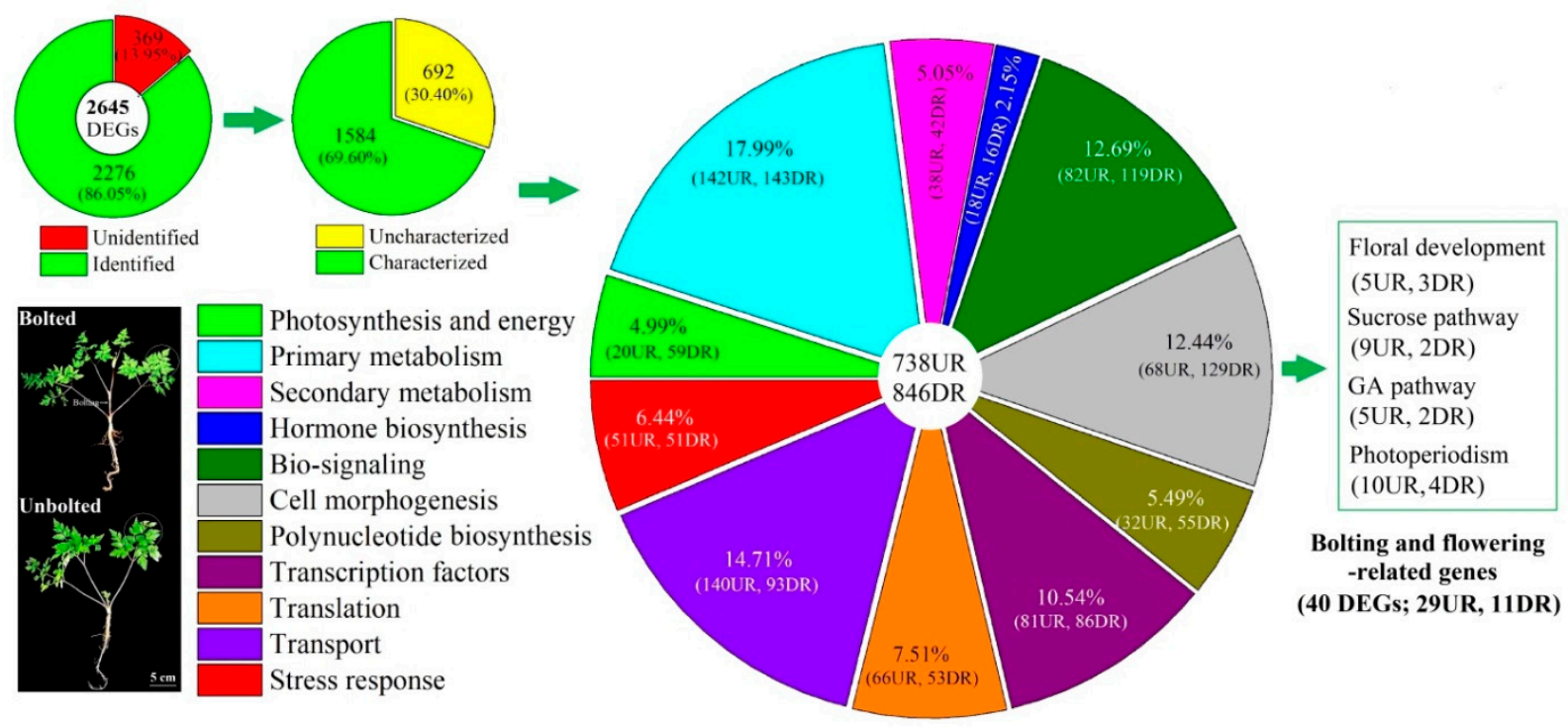

Figure 1. Distribution and classification of differentially expressed genes (DEGs) in bolted versus unbolted A. sinensis (UR, up-regulation; DR, down-regulation). 
Table 1. Summary of sequencing data for Angelica sinensis transcriptome.

\begin{tabular}{|c|c|c|}
\hline & Bolted & Unbolted \\
\hline \multicolumn{3}{|l|}{ Unfiltered data } \\
\hline Data of reads number (million) & 60.73 & 52.48 \\
\hline Reads length & 150 & 150 \\
\hline GC $(\%)$ & 44.69 & 45.12 \\
\hline Data of reads number $\times$ read length (million) & 9110 & 7872 \\
\hline Q20 (\%) & 98.50 & 98.47 \\
\hline Q30 (\%) & 95.25 & 95.18 \\
\hline \multicolumn{3}{|l|}{ Filtered data ${ }^{1}$} \\
\hline Data of reads number (million) & 60.66 & 52.41 \\
\hline Data of reads number $\times$ read length (million) & 9098 & 7862 \\
\hline Q20 (\%) & 98.56 & 98.53 \\
\hline Q30 (\%) & 95.34 & 95.26 \\
\hline \multicolumn{3}{|l|}{ Mapped data ${ }^{2}$} \\
\hline Data of unique mapped reads (million) & 44.70 & 37.40 \\
\hline Data of multiple mapped reads (million) & 7.80 & 6.40 \\
\hline Mapping ratio $(\%)$ & 86.56 & 83.57 \\
\hline \multicolumn{3}{|c|}{ Compiled data } \\
\hline Total number of unigenes & \multicolumn{2}{|c|}{72,502} \\
\hline Total Length (bp) (million) & \multicolumn{2}{|c|}{64.14} \\
\hline N50 (bp) & \multicolumn{2}{|c|}{1534} \\
\hline Max length (bp) & \multicolumn{2}{|c|}{15,601} \\
\hline Min length (bp) & \multicolumn{2}{|c|}{201} \\
\hline Average Length (bp) & \multicolumn{2}{|c|}{884} \\
\hline GC content $(\%)$ & \multicolumn{2}{|c|}{41.17} \\
\hline
\end{tabular}

Table 2. Database searches for collected $A$. sinensis nucleotide sequences.

\begin{tabular}{ccc}
\hline BLASTx Searching against Specific Platforms & Values & Percentage (\%) \\
\hline NR & 44,708 & 61.66 \\
SwissProt & 30,471 & 42.03 \\
KOG & 22,959 & 31.67 \\
KEGG & 18,056 & 24.90 \\
GO & 12,473 & 17.20 \\
\hline
\end{tabular}

\subsection{DEGs Linked with Bolting and Flowering}

Eight DEGs directly participate in floral development including: SOC1, MADS8, AGL8, AGL12, DEFA, AP1, AP2, and ANT (Table 3). The RELs of these genes were consistent with RPKM values, with up-regulation of 1.1-, 2.4-, 6.8-, 1.1-, 1.3-, and 1.3-fold for SOC1, MADS8, AGL8, AGL12, DEFA, and AP1, respectively, in bolted compared to unbolted plants; down-regulation of 0.6- and 0.9-fold was observed for AP2 and ANT (Figure 2A).

Eleven DEGs associated with sucrose pathway including: Suc metabolism (SUS1, SUS3, SUS7, INVA, INVB, INVE, and INV Inh) and starch metabolism (AMY1.1, BAM1, $B A M 3$, and $B A M 9$ ) (Table 3) were transcriptionally regulated so as to favor flowering in BPs. The RELs were consistent with RPKM values, with down-regulated 0.3-fold for the INV Inh gene, and up-regulated 1.3- to 6.1-fold for the other 10 genes in the BP compared to the UBP (Figure 2B). 
Table 3. Bolting/flowering genes differentially expressed in bolted and unbolted A. sinensis.

\begin{tabular}{|c|c|c|c|}
\hline Gene Name & Gene ID & Protein Name & $\log _{2}$ Ratio (B RPKM $\left._{\text {R }} / \mathrm{UB}_{\text {RPKM }}\right)$ \\
\hline \multicolumn{4}{|c|}{ Floral development (8) } \\
\hline \multicolumn{4}{|c|}{ Genes favoring flowering } \\
\hline SOC1 & XP_017245180.1 & MADS-box protein SOC1 & 1.06 \\
\hline MADS8 & XP_017257209.1 & MADS-box transcription factor 8 & 7.21 \\
\hline AGL8 & XP_017244085.1 & Agamous-like MADS-box protein AGL8 & 4.16 \\
\hline AGL12 & XP_017218759.1 & Agamous-like MADS-box protein AGL12 & 3.42 \\
\hline$D E F A$ & XP_017253634.1 & Floral homeotic protein DEFICIENS & 1.11 \\
\hline$A P 1$ & AGX01569.1 & Floral homeotic protein APETALA 1 & 4.29 \\
\hline \multicolumn{4}{|c|}{ Genes disfavoring flowering } \\
\hline$A P 2$ & XP_017231882.1 & \multirow{2}{*}{$\begin{array}{c}\text { Floral homeotic protein APETALA } 2 \\
\text { AP2-like ethylene-responsive transcription } \\
\text { factor ANT }\end{array}$} & -6.14 \\
\hline ANT & XP_017254585.1 & & -3.27 \\
\hline \multicolumn{4}{|c|}{ Sucrose pathway (11) } \\
\hline \multicolumn{4}{|c|}{ Genes favoring flowering } \\
\hline SUS1 & XP_017219197.1 & Sucrose synthase isoform 1 & 1.31 \\
\hline SUS3 & XP_017225961.1 & Sucrose synthase 3 & 1.40 \\
\hline SUS7 & XP_017244457.1 & Sucrose synthase 7 & -2.70 \\
\hline INVA & CAA76145.1 & $\begin{array}{c}\text { Alkaline/neutral invertase A, } \\
\text { mitochondrial }\end{array}$ & 1.41 \\
\hline$I N V B$ & XP_017254796.1 & Probable alkaline/neutral invertase B & 1.22 \\
\hline INVE & XP_017258042.1 & Alkaline/neutral invertase E, chloroplastic & 1.09 \\
\hline$A M Y 1.1$ & XP_017218607.1 & Alpha-amylase & 1.03 \\
\hline BAM1 & XP_017219233.1 & Beta-amylase 1 , chloroplastic & 1.62 \\
\hline$B A M 3$ & XP_017236738.1 & Beta-amylase 3, chloroplastic & 1.05 \\
\hline BAM9 & XP_017219710.1 & Inactive beta-amylase 9 & 1.30 \\
\hline \multicolumn{4}{|c|}{ Genes disfavoring flowering } \\
\hline INV Inh & KZV43516.1 & Invertase inhibitor & -1.83 \\
\hline \multicolumn{4}{|c|}{ GA pathway (7) } \\
\hline \multicolumn{4}{|c|}{ Genes favoring flowering } \\
\hline $\mathrm{KO}$ & XP_017253618.1 & Ent-kaurene oxidase, chloroplastic & 2.04 \\
\hline GA200X1 & XP_017239190.1 & Gibberellin 20 oxidase 1 & 1.77 \\
\hline \multicolumn{4}{|c|}{ Genes disfavoring flowering } \\
\hline GA2OX1 & API85599.1 & Gibberellin 2-beta-dioxygenase 1 & -1.41 \\
\hline GAI & XP_017238853.1 & DELLA protein GAI & -3.49 \\
\hline GA2OX6 & XP_017243791.1 & Gibberellin 2-beta-dioxygenase 6 & 2.53 \\
\hline GA2OX8 & XP_017220109.1 & Gibberellin 2-beta-dioxygenase 8 & 1.65 \\
\hline GAIP & XP_017217018.1 & DELLA protein GAIP & 2.15 \\
\hline \multicolumn{4}{|c|}{ Photoperiodic induction (14) } \\
\hline \multicolumn{4}{|c|}{ Genes favoring flowering } \\
\hline $\mathrm{CO} 3$ & XP_017232180.1 & Zinc finger protein $\mathrm{CO} 3$ & 2.58 \\
\hline COL2 & XP_017231361.1 & Zinc finger protein CONSTANS-LIKE 2 & 3.5 \\
\hline$H D 3 A$ & XP_017216959.1 & Protein HEADING DATE 3A & 13.41 \\
\hline FTIP1 & XP_019421416.1 & FT-interacting protein 1 & 2.13 \\
\hline$F D$ & XP_017256913.1 & Protein FD & 3.26 \\
\hline HDR1 & XP_019170400.1 & Protein HEADING DATE REPRESSOR 1 & 2.12 \\
\hline$S V P$ & XP_017245967.1 & MADS-box protein SVP & -1.25 \\
\hline \multicolumn{4}{|c|}{ Genes disfavoring flowering } \\
\hline COL3 & XP_017221909.1 & Zinc finger protein CONSTANS-LIKE 3 & -2.79 \\
\hline COL16 & XP_017244294.1 & Zinc finger protein CONSTANS-LIKE 16 & -1.33 \\
\hline AS1 & XP_017249788.1 & Transcription factor AS1 & -2.23 \\
\hline$C D F 2$ & XP_017221059.1 & Cyclic dof factor 2 & 3.03 \\
\hline MIP1A & XP_017253198.1 & B-box domain protein 30 & 2.58 \\
\hline MIP1B & XP_017253198.1 & B-box domain protein 31 & 3.50 \\
\hline$E F M$ & XP_017241902.1 & EARLY FLOWERING MYB PROTEIN & 1.12 \\
\hline
\end{tabular}



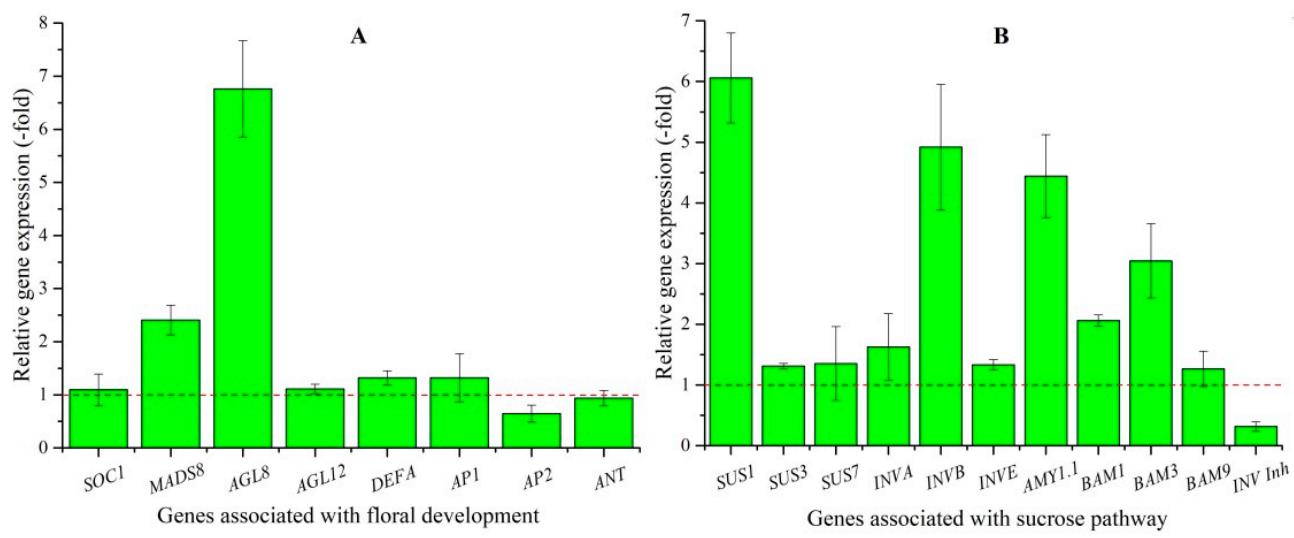

Figure 2. The relative expression level of genes associated with floral development (A) and sucrose pathway (B) in bolted compared with unbolted plants, as determined by qRT-PCR.

\subsection{Flower-Regulating DEGs Inarticulately Expressed with EBF}

Since GA accumulation can promote flowering, transcripts that encode for GA biosynthesis were screened for up-regulation in EBF plants. The 7 DEGs that are associated with GA signals include: GA biosynthesis (KO, GA2OX1, GA2OX6, GA2OX8, and GA20OX1) and GA mediated signaling pathway (GAI and GAIP) (Table 3). The RELs of the 7 genes were consistent with RPKM values, with up-regulated 1.1-, 1.02-, 2.3-, 5.2-, and 1.3-fold for the genes KO, GA20OX1, GA2OX6, GA2OX8, and GAIP, respectively, in the BP compared to the UBP, and with down-regulated 0.9- and 0.7-fold for the genes GA2OX1 and GAI in the BP (Figure 3A).
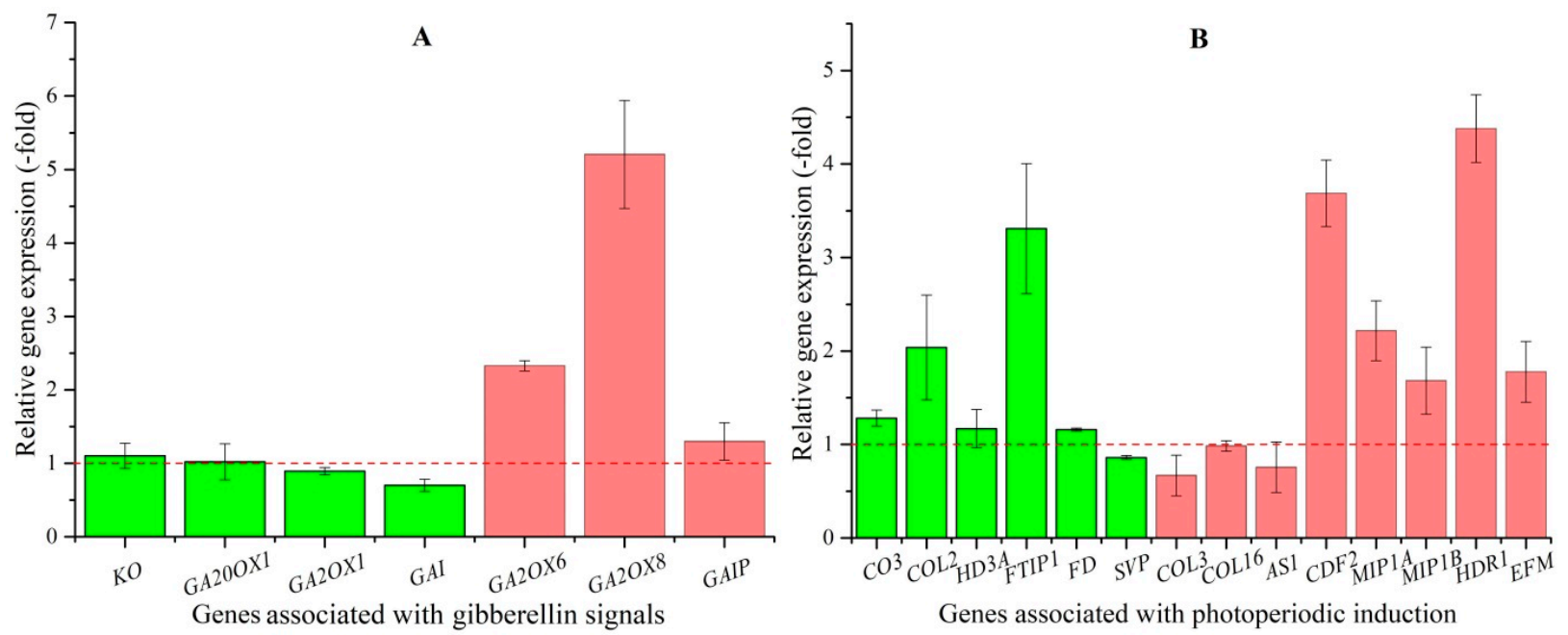

Figure 3. The relative expression level of genes associated with GA (A) and photoperiodic pathways (B) in bolted compared with unbolted plants, as determined by qRT-PCR. Column highlighted in green represents genes favoring flowering and red represents genes disfavoring flowering.

The 14 DEGs that are associated with photoperiodic induction include: $\mathrm{CO}$, COL2, COL3, COL16, FTIP1, FD, HDR1, HD3A, MIP1A, MIP1B, CDF2, SVP, EFM, and AS1 (Table 3). RPKM-based expression values of the 14 genes were validated by qRT-PCR, and their RELs were observed to be consistent with RPKM values, with up-regulated 1.3-, 2.0-, 3.3-, 1.2-, 4.4-, 1.2-, 2.2-, 1.7-, 3.7-, and 1.8-fold for the genes CO3, COL2, FTIP1, FD, HDR1, $H D 3 A, M I P 1 A, M I P 1 B, C D F 2$, and EFM, respectively, in the BP compared to the UBP, and with down-regulated 0.7-, 0.98-, 0.9-, and 0.8-fold for the genes COL3, COL16, SVP, and AS1 in the BP (Figure 3B). 


\subsection{Sucrose and GA Accumulation}

Flowering can be initiated by the accumulation of active GAs including $\mathrm{GA}_{1}, \mathrm{GA}_{3}$, $\mathrm{GA}_{4}$, and $\mathrm{GA}_{7}$. Interestingly, $\mathrm{GA}_{4}$ and $\mathrm{GA}_{1}$ as well as the up-stream precursors $\mathrm{GA}_{9}$ and $\mathrm{GA}_{20}$ had a 3.0-, 1.3-, 5.4-, and 4.2-fold increase in $\mathrm{BP}$ while the down-stream inactive forms of $\mathrm{GA}_{4}$ and $\mathrm{GA}_{1}, \mathrm{GA}_{8}$ had a 1.5-fold increase in UBP (Figure $4 \mathrm{~A}$ ). Since $\mathrm{GA}_{1}$ and $\mathrm{GA}_{4}$ exhibit higher floral induction activity than other GAs that are produced in plants [20], an elevated level of $\mathrm{GA}_{1}$ and $\mathrm{GA}_{4}$ may promote EBF. In contrast, an almost 2-fold decrease in soluble sugars in the BP was unexpected as elevated sugar is usually a driver of flowering [28] (Figure 4B).
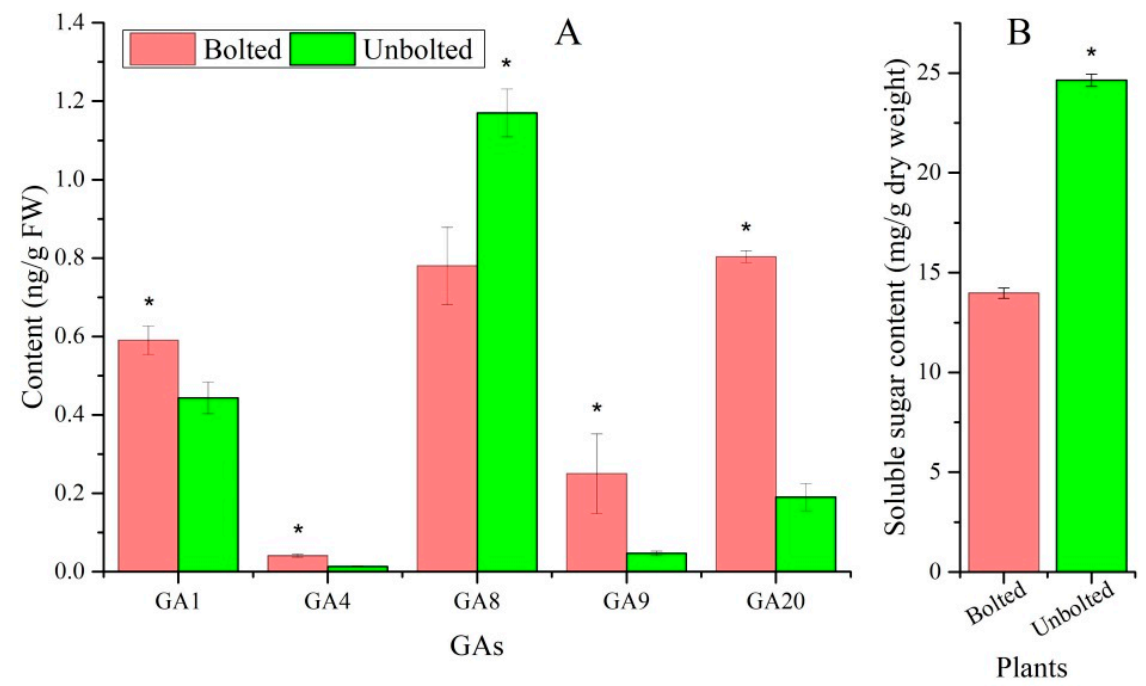

Figure 4. The contents of GAs (A) and soluble sugar (B) in bolted and unbolted plants, as determined by HPLC-MS/MS. An asterisk $\left(^{*}\right)$ represents a significant difference $(p<0.05)$ between BP and UBP.

\section{Discussion}

The SUPPRESSOR OF OVEREXPRESSION OF CONSTANS1 (SOC1) can integrate signals from the photoperiodism, vernalization, sucrose and GA pathways and regulate the expression of $L F Y$, which links floral induction and floral development, when associated with other MADS box genes [35]. MADS box proteins regulate different developmental processes including flowering time, floral meristem identity, and floral organ development [36]. MADS8, which is structurally related to the AGL2 family, is involved in controlling flowering time [37]. AGL8 promotes early floral meristem identity in synergy with AP1 and CAULIFLOWER [38]. AGL12 acts as promoter of the flowering transition through up-regulation of SOC, FT, and LFY [39]. DEFICIENS (DEFA) is involved in the genetic control of floral development [40]. APETALA1 (AP1) and AP2 are required for the transition of an inflorescence meristem into a floral meristem and promote early floral meristem identity, with $A P 1$ regulating positively $A G$ in cooperation with $L F Y$, while $A P 2$ represses $A G$ by recruiting the transcriptional corepressor TPL and HDA19 [41,42]. AINTEGUMENTA (ANT), a member of the AP2-like family, is involved in flower organs initiation and development and mediates $A G$ down-regulation [43,44]. Previous studies on $A$. sinensis found that the $S O C 1$ was down-regulated and the $A G$ was up-regulated in 2-year-old plants during transition from vegetative to flower bud differentiation [28]; the $A G L 62, P M A D S 1$, and DEFA were up-regulated in 3-year-old plants at different growth and development stages [29]. In this study, positive regulators of flowering in the floral development pathway were observed to be up-regulated in EBF plants, while genes that disfavor flowering ( $A P 2$ and $A N T$ ) were down-regulated, suggesting that transcription regulation of these genes may well be a driver for $A$. sinensis EBF.

Suc and its cleavage products glucose (Glc) and fructose (Fru) are central molecules for cellular biosynthesis and signal transduction throughout a plant's life cycle [45]. In this 
study, Suc synthases (SUSs) that are encoded by three SUS1, SUS3, and SUS7 genes catalyze a reversible conversion of Suc and UDP to UDP-Glc and Fru [46,47]; Alkaline/neutral invertases (INVs) that are encoded by three INVA, INVB, and INVE genes catalyze an irreversible hydrolysis of Suc to Glc and Fru [48-50]; and the invertase inhibitor (INV Inh) inhibits the INV activity by forming a complex with INV [51]. Two kinds of amylase enzymes including $\alpha$-amylase (AMY) and $\beta$-amylase (BAM) could respectively produce $\alpha$-maltose and $\beta$-maltose through the hydrolysis of amylopectin and amylose [52]. In this study, four DEGs encoding amylase enzymes include: $A M Y 1.1$, which can increase enzyme activity via accessory binding sites on the protein surface, $B A M 1$ and $B A M 3$, which play important roles in starch degradation and maltose metabolism, and BAM9, which is inactive due to lack the conserved Glu active site [52-54]. The SUS6 and AMY2 were found to be up-regulated in 3-year-old plants of $A$. sinensis at different development stages [29]. Here, since the genes (SUS1, SUS3, SUS7, INVA, INVB, INVE, AMY1.1, BAM1, BAM3, and $B A M 9$ ) that favor flowering were up-regulated and the INV Inh gene that disfavors flowering was down-regulated, transcriptional regulation of sucrose pathway is consistent with EBF.

While genes associated with GA biosynthesis and GA mediated signaling were differentially regulated in $\mathrm{BP}$ versus UBP, the genes did not exhibit coherent transcriptional regulation with $\mathrm{EBF}$, suggesting that transcriptional regulation of GA mediated genes is not a driver of early bolting. Previous studies on A. sinensis found that the GA20OX had no difference change during transition from vegetative to flower bud differentiation [28]; while the GA2OX1 and GA2OX8 were down-regulated at different growth and development stages [29]. For example, with GA mediated signaling, DELLA proteins GA-INSENSITIVE (GAI) and GAIP function as inhibitors by interacting in large multiprotein complexes that repress transcription of GA-inducible genes [55-57]. Inconsistent with promoting flowering, the GAIP is transcriptionally up-regulated in BP versus UBP. Inconsistency is also observed in genes that encode GA biosynthesis with a subset of genes up-regulated such as $K O$, which catalyzes the conversion of ent-kaurene to kaurenoic acid early in the biosynthetic pathway [58] as well as GA20OX1, which converts $\mathrm{GA}_{12} / \mathrm{GA}_{53}$ to $\mathrm{GA}_{9} / \mathrm{GA}_{20}$ [59] later in the pathway (Figure S13), while GA2OX catalyzes 2-beta-hydroxylation of GA precursors, rendering them unable to be converted to active GAs is up-regulated under the same condition that promotes flowering (BP). This incoherent transcriptional regulation of GA biosynthesis and signaling for EBF suggests that early bolting may be regulated by events downstream of flowering signaling such as GA and/or sugar accumulation.

While CONSTANS-LIKE (COL) genes are regulators in the photoperiod pathway and flowering, transcripts in this pathway were also inconsistently induced providing an inarticulate signal for plant flowering, which was in accordance with previous findings with the CO, COL2, and COL16 up-regulated while the COL4 and COL10 down-regulated in A. sinensis [28,29]. For example, while both CO3 and COL3 function as floral activators, the two genes were transcriptionally up- and down-regulated, respectively, when comparing BP with UBP. Specifically, $\mathrm{CO} 3$ up-regulates the expression of Heading date $3 a$ (HD3A) and FLOWERING LOCUS T-LIKE (FTL) under LD conditions [60,61]. FT-interacting protein 1 (FTIP1) is an essential regulator required for the export of FT protein from the phloem companion cells to sieve elements through the plasmodesmata under LD conditions [62] and was observed to be up-regulated in BP. The FT protein acts as a long-distance signal to induce flowering [63] and FLOWERING LOCUS D $(F D)$ interacts with FT protein to activate the downstream floral meristem identity genes $A P 1$ to initiate floral development [64,65]. While this is consistent with flower induction that is observed with $\mathrm{BP}$, there are several transcriptional responses that are not down-regulated as expected. For example, $A S 1$, a positive regulator of flowering that binds to the promoter of FT [66], was found to be down-regulated in BP. CDF2, a transcriptional repressor that delays flowering by repressing $C O$ transcription under LD conditions [25], was found to be up-regulated almost 4-fold in BP compared with UBP. MIP1A and MIP1B, which repress flowering by forming heterodimeric complexes that sequester $\mathrm{CO}$ and $\mathrm{COL}$ proteins into non-functional complexes [26], were also found to be up-regulated in BP. Another inconsistent 
transcriptional response for flowering is up-regulation of HEADING DATE REPRESSOR 1 (HDR1), a flowering suppressor that up-regulates HD1 in LD conditions [67]. Previous studies on A. sinensis also found that the FTIP1, CDF2, MIP1A, and MIP1B were up-regulated at different growth and development stages [29]. Again, inconsistent regulation of photoperiod pathway transcripts associated with flowering in BP suggests down-stream signaling involvement in early bolting. Among the 40 DEGs associated with flowering, 29 genes showed coherent transcriptional regulation with EBF, while 11 genes were incoherent including: GA2OX6, GA2OX8, GAIP, HDR1, COL3, COL16, AS1, CDF2, MIP1A, MIP1B, and EFM. Extensive experiments have demonstrated that gene expression depends on the plant organ and even on the tissues in each organ [68-70]. In this study, the total RNA samples were extracted from the equivalent weight of the leaves and roots from BP and UBP, in theory, the level of gene expression obtained in the experiments is an average value of the expression in the leaves and roots, which could explain the incoherent transcriptional regulation of GA pathway and photoperiodic induction for EBF. For the 11 incoherent genes, their regulatory mechanisms need further validation by detecting gene expression in single organ.

Flowering is a process in which plants transition from vegetative to reproductive growth via a complex pathway of signaling networks. The DEGs observed comparing $\mathrm{BP}$ and UBP suggests transcription-based regulation of EBF. Specifically, genes associated with floral development and sucrose signaling are transcriptionally correlated with bolting (Figure 5). For the floral development, $\mathrm{SOC1}$ can integrate signals from the photoperiodic, GA and sucrose pathways to initiate early floral meristem identity by regulating the over-expression of $L F Y$; meanwhile, AP1 in synergy with MADS, AGL8, and AGL12 that are repressed by $A P 2$ and $A N T$, promote early floral meristem identity. Lastly, the early floral meristem identity induces early bolting and flowering of $A$. sinensis plants. For sugar signaling, over-expression of genes $A M Y 1.1, B A M 1$, and BAM3 enhances starch degradation while differential expression SUSs, INVs, and INV Inh cleavage Suc to Glc and Fru can also promote $S O C 1$ expression.

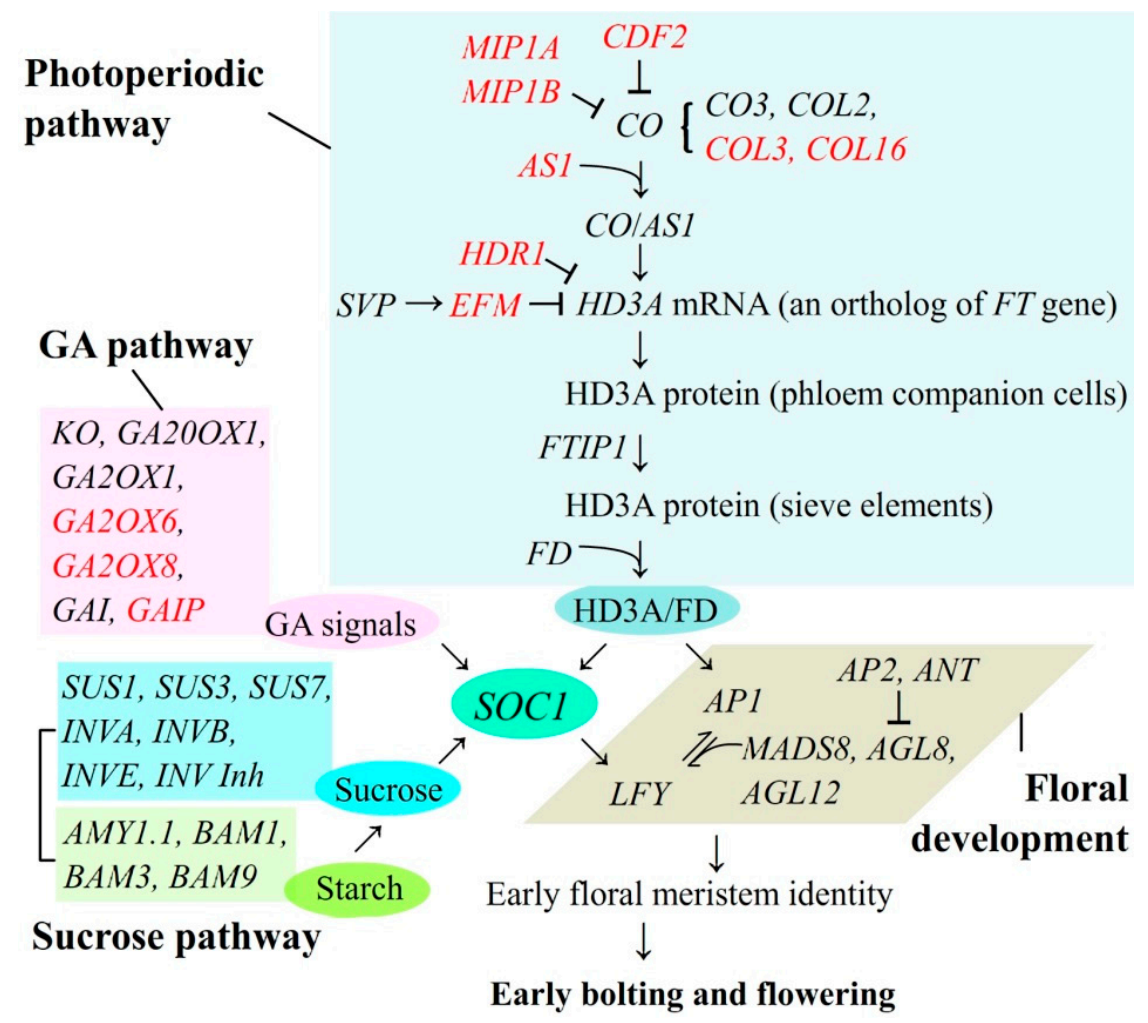

Figure 5. Schematic representation of proposed pathways of DEGs for regulating early bolting and flowering in A. sinensis. Genes highlighted in black represent favoring flowering and genes highlighted in red represent disfavoring flowering. 


\section{Conclusions}

The DEGs observed comparing BP and UBP suggests transcription-based regulation of EBF. This transcriptomic and analysis focuses on four pathways that can mediate a transition from vegetative to reproductive growth: photoperiodic, GA signaling, autonomous, and floral development. While genes associated with EBF have been identified and mapped here, a causative role of these genes in activating and/or regulating EBF will require the knocking out of specific genes via a CRISPR/Cas 9 system.

Supplementary Materials: The following are available online at https:/ / www.mdpi.com/article / 10.3390/plants10091931/s1, Figure supplemental legends: Figure S1: Growth and development of Angelica sinensis in a commercial production process; Figure S2: Two-year-old bolted and unbolted plants of A. sinensis; Figure S3: The cluster analysis of the 40 DEGs comparing with the families in Arabidopsis thaliana; Figure S4: Representative chromatograms of reference standard of $\mathrm{GA}_{1}, \mathrm{GA}_{4}$, $\mathrm{GA}_{8}, \mathrm{GA}_{9}$, and $\mathrm{GA}_{20}$; Figure S5: Representative chromatograms of bolted (A) and unbolted plants (B) of A. sinensis; Figure S6: Length distribution of assembled unigenes; Figure S7: Read distribution of unigenes; Figure S8: Basic annotation for all unigenes; Figure S9: Top 10 plant species distribution of the total homologous sequences; Figure S10: Distribution of unigenes in the transcriptome with KOG functional classification. Sequences have a KOG classification among 25 categories; Figure S11: Functional classifications of GO terms of all assembled unigenes; Figure S12: Number of DEGs, correlation and volcano plot for unbolted versus bolted plants; Figure S13: The GA biosynthesis pathways and the differentially expressed genes are highlighted in red. Table supplemental legends: Table S1: Sequences of primer used in the qRT-PCR analysis; Table S2: Calibration curves of GA 1 , $\mathrm{GA}_{4}, \mathrm{GA}_{8}, \mathrm{GA}_{9}$, and $\mathrm{GA}_{20}$.

Author Contributions: M.L.: methodology, supervision and writing—original draft. J.L.: data curation, formal analysis, investigation and validation. J.W.: project administration and resources. P.W.P.: conceptualization and writing-review and editing. All authors have read and agreed to the published version of the manuscript.

Funding: This work was financially supported by National Natural Science Foundation of China (32160083), China Agriculture Research System of MOF and MARA (CARS-21), Gansu Agricultural University (GSCS-2018-1 and Gaufx-02J04), and Key talent projects of Gansu Province (2020RCXM103).

Data Availability Statement: The datasets generated during the current study are publicly available at National Center for Biotechnology Information (NCBI), with Accession: PRJNA591308 and ID: 591308 (https:/ / www.ncbi.nlm.nih.gov/bioproject/PRJNA591308, accessed on 20 August 2021).

Conflicts of Interest: The authors declare that there are no conflicting interests.

\section{References}

1. Li, M.F.; Liu, X.Z.; Wei, J.H.; Zhang, Z.; Chen, S.J.; Liu, Z.H.; Xing, H. Selection of high altitude planting area of Angelica sinensis based on biomass, bioactive compounds accumulation and antioxidant capacity. Chin. Tradit. Herbal Drugs 2020, 51, $474-481$.

2. Xu, X.Q.; Zhang, X.B.; Chen, J.; Zhao, W.L.; Jin, L. Study on ecological suitability of Angelica sinensis in Gansu Province. Chin. Tradit. Herbal Drugs 2020, 51, 3304-3307.

3. Zhang, H.Y.; Bi, W.G.; Yu, Y.; Liao, W.B. Angelica sinensis (Oliv.) Diels in China: Distribution, cultivation, utilization and variation. Genet. Resour. Crop Evol. 2012, 59, 607-613. [CrossRef]

4. Upton, R. American Herbal Pharmacopoeia and Therapeutic compendium: Dang Gui Root-Angelica sinensis (Oliv.); American Herbal Pharmacopoeia: Scotts Valley, CA, USA, 2003; pp. 1-41.

5. Ma, J.P.; Guo, Z.B.; Jin, L.; Li, Y.D. Phytochemical progress made in investigations of Angelica sinensis (Oliv.) Diels. Chin. J. Nat. Med. 2015, 13, 241-249. [CrossRef]

6. Wei, W.L.; Zeng, R.; Gu, C.M.; Qu, Y.; Huang, L.F. Angelica sinensis in China-A review of botanical profile, ethnopharmacology, phytochemistry and chemical analysis. J. Ethnopharmacol. 2016, 190, 116-141. [CrossRef] [PubMed]

7. Chao, W.W.; Hong, Y.H.; Chen, M.L.; Lin, B.F. Inhibitory effects of Angelica sinensis ethyl acetate extract and major compounds on NF- $\mathrm{KB}$ trans-activation activity and LPS-induced inflammation. J. Ethnopharmacol. 2010, 129, 244-249. [CrossRef]

8. Wang, L.Y.; Tang, Y.P.; Liu, X.; Zhu, M.; Tao, W.W.; Li, W.X.; Duan, J.A. Effects of ferulic acid on antioxidant activity in Angelicae sinensis Radix, Chuan xiong Rhizoma, and their combination. Chin. J. Nat. Med. 2015, 13, 401-408.

9. Wang, B.H.; Ou-Yang, J.P. Pharmacological actions of sodium ferulate in cardiovascular system. Cardiovasc. Drug Rev. 2005, 23, 161-172. [CrossRef] [PubMed] 
10. Li, M.F.; Kang, T.L.; Jin, L.; Wei, J.H. Research progress on bolting and flowering of Angelica sinensis and regulation pathways. Chin. Tradit. Herbal Drugs 2020, 51, 5894-5899.

11. Huang, L.Q.; Jin, L. Suitable Technology for Production and Processing of Angelica Sinensis; Pharmaceutical Science and Technology Press: Beijing, China, 2018; pp. 1-14.

12. Zhang, Z.; Liu, X.Z.; Bao, Y.J.; Li, J.; Cao, X.L.; Li, M.F. Selection of cropping rotations of Angelica sinensis based on biomass, bioactive compounds accumulation and antioxidant capacity. J. Gansu Agric. Univ. 2018, 53, 86-89.

13. Wang, W.J. Analysis and control of early bolting characteristic of Angelica sinensis. J. Northwest Univ. (Nat. Sci. Ed.) 1977, 7, 32-39.

14. Wang, W.J. Technology and principle of seedling frozen storage of Angelica sinensis. J. Chin. Med. Mat. 1979, 3, 1-4.

15. Lin, H.M.; Wu, Y.A.; Cao, Z.F.; Lv, S.L.; Mao, X.J. Influence of sun shade cultivation on premature bolting in Angelica sinensis and growth environment factors. Chin. J. Exp. Trad. Med. Formula. 2010, 16, 79-83.

16. Qiu, D.Y.; Lin, H.M.; Fang, Z.S.; Li, Y.D. Effects of seedlings with different root diameters on Angelica sinensis early bolting and physiological changes during the medicine formation period. Acta Pratac. Sin. 2010, 19, 100-105.

17. Qiu, D.Y.; Lin, H.M.; Chen, Y.; Li, Y.D.; Guo, F.X. Effects of latitude, longitude and altitude on Angelica growth and early bolting in medicine formation period. Acta Agrestia Sin. 2010, 18, 838-843.

18. Qi, J.T.; Lin, H.M.; Liu, X.Z. Preliminary study on the effect of nitrogen and phosphorus fertilizer on bolting rate of Angelica sinensis. J. Chin. Med. Mater. 2004, 27, 82-83.

19. Li, M.S.; Yu, Z.Y. Research on Prevention of Early Bolting of Angelica sinensis. Chin. Tradit. Herbal Drugs 1979, 57, 34-38, 49.

20. Taiz, L.; Zeiger, E. Plant Physiology, 5th ed.; Sinauer Associates, Inc., Publishers: Sunderland, MA, USA, 2010 ; pp. 559-590.

21. Michaels, S.D.; Amasino, R.M. Memories of winter: Vernalization and the competence to flower. Plant Cell Environ. 2000, 23, 1145-1154. [CrossRef]

22. Chen, L.; Cheng, J.C.; Castle, L.; Sung, Z.R. EMF genes regulate Arabidopsis inflorescence development. Plant Cell 1997, 9, 2011-2024. [PubMed]

23. Goodrich, J.; Puangsomlee, P.; Martin, M.; Long, D.; Meyerowitz, E.M.; Coupland, G. A Polycomb-group gene regulates homeotic gene expression in Arabidopsis. Nature 1997, 386, 44-51. [CrossRef] [PubMed]

24. Piñeiro, M.; Gómez-Mena, C.; Schaffer, R.; Martínez-Zapater, J.M.; Coupland, G. EARLY BOLTING IN SHORT DAYS is related to chromatin remodeling factors and regulates flowering in Arabidopsis by repressing FT. Plant Cell 2003, 15, 1552-1562. [CrossRef]

25. Fornara, F.; Panigrahi, K.C.; Gissot, L.; Sauerbrunn, N.; Ruehl, M.; Jarillo, J.A.; Coupland, G. Arabidopsis DOF transcription factors act redundantly to reduce CONSTANS expression and are essential for a photoperiodic flowering response. Dev. Cell 2009, 17, 75-86. [CrossRef]

26. Graeff, M.; Straub, D.; Eguen, T.; Dolde, U.; Rodrigues, V.; Brandt, R.; Wenkel, S. Microprotein-mediated recruitment of CONSTANS into a TOPLESS trimeric complex represses flowering in Arabidopsis. Plos Genet. 2016, 12, e1005959. [CrossRef]

27. Lu, Z.Q.; Zhang, J.W.; Ren, L.R.; Huang, H.Y.; Ma, Z.C.; Qi, J.T. Analysis on physiological and biochemical characteristics of bolting Angelica sinensis plant. Chin. Tradit. Herbal Drugs 2011, 42, 2326-2329.

28. Yu, G.; Zhou, Y.; Yu, J.J.; Hu, X.Q.; Tang, Y.; Yan, H.; Duan, J.A. Transcriptome and digital gene expression analysis unravels the novel mechanism of early flowering in Angelica sinensis. Sci. Rep. 2019, 9, 10035. [CrossRef] [PubMed]

29. Li, J.; Li, M.L.; Zhu, T.T.; Zhang, X.N.; Li, M.F.; Wei, J.H. Integrated transcriptomics and metabolites at different growth stages reveals the regulation mechanism of bolting and flowering of Angelica sinensis. Plant Biol. 2021, 23, 574-582. [CrossRef] [PubMed]

30. Grabherr, M.G.; Haas, B.J.; Yassour, M.; Levin, J.Z.; Thompson, D.A.; Amit, I.; Adiconis, X.; Fan, L.; Raychowdhury, R.; Zeng, Q.; et al. Full-length transcriptome assembly from RNA-Seq data without a reference genome. Nat. Biotechnol. 2011, $29,644-652$. [CrossRef]

31. Mortazavi, A.; Williams, B.; McCue, K.; Schaeffer, L.; Wold, B. Mapping and quantifying mammalian transcriptomes by RNA-Seq. Nat. Methods 2008, 5, 621-628. [CrossRef]

32. Conesa, A.; Gotz, S.; Garcia-Gomez, J.M.; Terol, J.; Talon, M.; Robles, M. Blast2GO: A universal tool for annotation, visualization and analysis in functional genomics research. Bioinformatics 2005, 21, 3674-3676. [CrossRef] [PubMed]

33. Willems, E.; Leyns, L.; Vandesompele, J. Standardization of real-time PCR gene expression data from independent biological replicates. Anal. Biochem. 2008, 379, 127-129. [CrossRef] [PubMed]

34. Dubois, M.; Gilles, K.A.; Hamilton, J.K.; Rebers, P.A.; Smith, F. Colorimetric method for determination of sugars and related substances. Anal. Chem. 1956, 28, 350-356. [CrossRef]

35. Lee, J.; Oh, M.; Park, H.; Lee, I. SOC1 translocated to the nucleus by interaction with AGL24 directly regulates leafy. Plant J. 2008, 55, 832-843. [CrossRef]

36. Theissen, G.; Becker, A.; Di Rosa, A.; Kanno, A.; Kim, J.T.; Munster, T.; Winter, K.U.; Saedler, H. A short history of MADS-box genes in plants. Plant Mol. Biol. 2000, 42, 115-149. [CrossRef] [PubMed]

37. Kang, H.G.; Jang, S.; Chung, J.E.; Cho, Y.G.; An, G. Characterization of two rice MADS box genes that control flowering time. Mol. Cells 1997, 7, 559-566. [PubMed]

38. Ferrandiz, C.; Gu, Q.; Martienssen, R.; Yanofsky, M.F. Redundant regulation of meristem identity and plant architecture by FRUITFULL, APETALA1 and CAULIFLOWER. Development 2000, 127, 725-734. [CrossRef]

39. Tapia-Lopez, R.; Garcia-Ponce, B.; Dubrovsky, J.G.; Garay-Arroyo, A.; Perez-Ruiz, R.V.; Kim, S.H.; Acevedo, F.; Pelaz, S.; AlvarezBuylla, E.R. An AGAMOUS-related MADS-box gene, XAL1 (AGL12), regulates root meristem cell proliferation and flowering transition in Arabidopsis. Plant Physiol. 2008, 146, 1182-1192. [CrossRef] 
40. Sommer, H.; Beltrán, J.P.; Huijser, P.; Pape, H.; Lönnig, W.E.; Saedler, H.; Schwarz-Sommer, Z. Deficiens, a homeotic gene involved in the control of flower morphogenesis in Antirrhinum majus: The protein shows homology to transcription factors. EMBO J. 1990, 9, 605-613. [CrossRef]

41. Gregis, V.; Sessa, A.; Dorca-Fornell, C.; Kater, M.M. The Arabidopsis floral meristem identity genes AP1, AGL24 and SVP directly repress class B and C floral homeotic genes. Plant J. 2009, 60, 626-637. [CrossRef]

42. Krogan, N.T.; Hogan, K.; Long, J.A. APETALA2 negatively regulates multiple floral organ identity genes in Arabidopsis by recruiting the co-repressor TOPLESS and the histone deacetylase HDA19. Development 2012, 139, 4180-4190. [CrossRef]

43. Elliott, R.C.; Betzner, A.S.; Huttner, E.; Oakes, M.P.; Tucker, W.Q.J.; Gerentes, D.; Perez, P.; Smyth, D.R. AINTEGUMENTA, an APETALA2-like gene of Arabidopsis with pleiotropic roles in ovule development and floral organ growth. Plant Cell 1996, 8, $155-168$.

44. Krizek, B.A.; Prost, V.; Macias, A. AINTEGUMENTA promotes petal identity and acts as a negative regulator of AGAMOUS. Plant Cell 2000, 12, 1357-1366. [CrossRef]

45. Smeekens, S.; Ma, J.; Hanson, J.; Rolland, F. Sugar signals and molecular networks controlling plant growth. Curr. Opin. Plant Biol. 2010, 3, 273-278. [CrossRef] [PubMed]

46. Angeles-Nunez, J.G.; Tiessen, A. Arabidopsis sucrose synthase 2 and 3 modulate metabolic homeostasis and direct carbon towards starch synthesis in developing seeds. Planta 2010, 232, 701-718. [CrossRef] [PubMed]

47. Geigenberger, P.; Stitt, M. Sucrose synthase catalyzes a readily reversible-reaction in vivo in developing potato tubers and other plant tissues. Planta 1993, 189, 329-339. [CrossRef] [PubMed]

48. Tamoi, M.; Tabuchi, T.; Demuratani, M.; Otori, K.; Tanabe, N.; Maruta, T.; Shigeoka, S. Point mutation of a plastidic invertase inhibits development of the photosynthetic apparatus and enhances nitrate assimilation in sugar-treated Arabidopsis seedlings. J. Biol. Chem. 2010, 285, 15399-15407. [CrossRef] [PubMed]

49. Vargas, W.A.; Pontis, H.G.; Salerno, G.L. New insights on sucrose metabolism: Evidence for an active A/N-Inv in chloroplasts uncovers a novel component of the intracellular carbon trafficking. Planta 2008, 227, 795-807. [CrossRef]

50. Xiang, L.; Le Roy, K.; Bolouri-Moghaddam, M.R.; Vanhaecke, M.; Lammens, W.; Rolland, F.; Van den Ende, W. Exploring the neutral invertase-oxidative stress defence connection in Arabidopsis thaliana. J. Exp. Bot. 2011, 62, 3849-3862. [CrossRef] [PubMed]

51. Rausch, T.; Greiner, S. Plant protein inhibitors of invertases. Biochim. Biophys. Acta 2004, 1696, 253-261. [CrossRef]

52. Fulton, D.C.; Stettler, M.; Mettler, T.; Vaughan, C.K.; Li, J.; Francisco, P.; Gil, M.; Reinhold, H.; Eicke, S.; Messerli, G.; et al. Beta-AMYLASE4, a noncatalytic protein required for starch breakdown, acts upstream of three active beta-amylases in Arabidopsis chloroplasts. Plant Cell 2008, 20, 1040-1058. [CrossRef]

53. Edner, C.; Li, J.; Albrecht, T.; Mahlow, S.; Hejazi, M.; Hussain, H.; Kaplan, F.; Guy, C.; Smith, S.M.; Steup, M.; et al. Glucan, water dikinase activity stimulates breakdown of starch granules by plastidial beta-amylases. Plant Physiol. 2007, 145, 17-28. [CrossRef]

54. Lu, Y.; Gehan, J.P.; Sharkey, T.D. Daylength and circadian effects on starch degradation and maltose metabolism. Plant Physiol. 2005, 138, 2280-2291. [CrossRef]

55. Blázquez, M.A.; Weigel, D. Integration of floral inductive signals in Arabidopsis. Nature 2000, 404, 889-892. [CrossRef] [PubMed]

56. Fu, X.; Sudhakar, D.; Peng, J.; Richards, D.E.; Christou, P.; Harberd, N.P. Expression of Arabidopsis GAI in transgenic rice represses multiple gibberellin responses. Plant Cell 2001, 13, 1791-1802. [CrossRef] [PubMed]

57. Fukazawa, J.; Teramura, H.; Murakoshi, S.; Nasuno, K.; Nishida, N.; Ito, T.; Yoshida, M.; Kamiya, Y.; Yamaguchi, S.; Takahashi, Y. DELLAs function as coactivators of GAI-ASSOCIATED FACTOR1 in regulation of gibberellin homeostasis and signaling in Arabidopsis. Plant Cell 2014, 26, 2920-2938. [CrossRef] [PubMed]

58. Morrone, D.; Chen, X.; Coates, R.M.; Peters, R.J. Characterization of the kaurene oxidase CYP701A3, a multifunctional cytochrome P450 from gibberellin biosynthesis. Biochem. J. 2010, 431, 337-344. [CrossRef] [PubMed]

59. Rieu, I.; Ruiz-Rivero, O.; Fernandez-Garcia, N.; Griffiths, J.; Powers, S.J.; Gong, F.; Linhartova, T.; Eriksson, S.; Nilsson, O.; Thomas, S.G.; et al. The gibberellin biosynthetic genes AtGA20ox1 and AtGA20ox2 act, partially redundantly, to promote growth and development throughout the Arabidopsis life cycle. Plant J. 2008, 53, 488-504. [CrossRef]

60. Kojima, S.; Takahashi, Y.; Kobayashi, Y.; Monna, L.; Sasaki, T.; Araki, T.; Yano, M. Hd3a, a rice ortholog of the Arabidopsis FT gene, promotes transition to flowering downstream of Hd1 under short-day conditions. Plant Cell Physiol. 2002, 43, 1096-1105. [CrossRef]

61. Kim, S.K.; Yun, C.H.; Lee, J.H.; Jang, Y.H.; Park, H.Y.; Kim, J.K. OsCO3, a CONSTANS-LIKE gene, controls flowering by negatively regulating the expression of $F T$-like genes under SD conditions in rice. Planta 2008, 228, 355-365. [CrossRef]

62. Liu, L.; Liu, C.; Hou, X.; Xi, W.; Shen, L.; Tao, Z.; Wang, Y.; Yu, H. FTIP1 is an essential regulator required for florigen transport. PloS Biol. 2012, 10, e1001313. [CrossRef]

63. Corbesier, L.; Vincent, C.; Jang, S.; Fornara, F.; Fan, Q.; Searle, I.; Giakountis, A.; Farrona, S.; Gissot, L.; Turnbull, C.; et al. FT protein movement contributes to long-distance signaling in floral induction of Arabidopsis. Science 2007, 316, 1030-1033. [CrossRef] [PubMed]

64. Abe, M.; Kobayashi, Y.; Yamamoto, S.; Daimon, Y.; Yamaguchi, A.; Ikeda, Y.; Ichinoki, H.; Notaguchi, M.; Goto, K.; Araki, T. FD, a bZIP protein mediating signals from the floral pathway integrator FT at the shoot apex. Science 2005, 309, 1052-1056. [CrossRef]

65. Wigge, P.A.; Kim, M.C.; Jaeger, K.E.; Busch, W.; Schmid, M.; Lohmann, J.U.; Weigel, D. Integration of spatial and temporal information during floral induction in Arabidopsis. Science 2005, 309, 1056-1059. [CrossRef] [PubMed] 
66. Song, Y.H.; Lee, I.; Lee, S.Y.; Imaizumi, T.; Hong, J.C. CONSTANS and ASYMMETRIC LEAVES 1 complex is involved in the induction of FLOWERING LOCUS T in photoperiodic flowering in Arabidopsis. Plant J. 2012, 69, 332-342. [CrossRef] [PubMed]

67. Sun, X.; Zhang, Z.; Wu, J.; Cui, X.; Feng, D.; Wang, K.; Xu, M.; Zhou, L.; Han, X.; Gu, X.; et al. The Oryza sativa regulator HDR1 associates with the kinase OsK4 to control photoperiodic flowering. PLoS Genet. 2016, 12, e1005927. [CrossRef] [PubMed]

68. van der Hoeven, C.; Dietz, A.; Landsmann, J. Variability of organ-specific gene expression in transgenic tobacco plants. Transgenic Res. 1994, 3, 159-166. [CrossRef]

69. Tao, S.Q.; Li, J.; Gu, X.G.; Wang, Y.A.; Xia, Q.; Qin, B.; Zhu, L. Quantitative analysis of ATP sulfurylase and selenocysteine methyltransferase gene expression in different organs of tea plant (Camellia sinensis). Amer. J. Plant Sci. 2012, 3, 51-59. [CrossRef]

70. Che, P.; Lall, S.; Nettleton, D.; Howell, S.H. Gene expression programs during shoot, root, and callus development in Arabidopsis tissue culture. Plant Physiol. 2006, 141, 620-637. [CrossRef] 